Tropical Journal of Pharmaceutical Research April 2016; 15 (4): 861-867

ISSN: $1596-5996$ (print); 1596-9827 (electronic)

(C) Pharmacotherapy Group, Faculty of Pharmacy, University of Benin, Benin City, 300001 Nigeria.

All rights reserved.

Available online at http://www.tjpr.org

Original Research Article

http://dx.doi.org/10.4314/tjpr.v15i4.28

\title{
Comparison of access to medicines between Klang Valley and East Coast of peninsular Malaysia for children living in poor households
}

\author{
Asmalita Saiful ${ }^{1}$, Muslimah Ithnin ${ }^{1}$, Mohd Dzulkhairi Mohd Rani ${ }^{1}$, Nor Azila \\ Noh', Nazefah Abdul Hamid ${ }^{1}$, Isa Naina Mohamed ${ }^{2}$, Redhwan Al-Naggar ${ }^{3}$ and \\ Khairun Nain Bin Nor Aripin ${ }^{1 *}$
}

${ }^{1}$ Faculty of Medicine and Health Sciences, Universiti Sains Islam Malaysia, ${ }^{2}$ Faculty of Medicine, Universiti Kebangsaan Malaysia, Kuala Lumpur, ${ }^{3}$ Faculty of Medicine, Universiti Teknologi MARA, Selangor, Malaysia

*For correspondence: Email: khairun@usim.edu.my; Tel: +603 4289 2446; Fax: +603 42892477

\begin{abstract}
Purpose: To compare access to medicines in children living in poor households (income of USD1/person/day) between urbanised Klang Valley and rural East Coast of Peninsular Malaysia. Methods: A semi-structured interview was conducted with caregivers to determine demographics, access to medicines, knowledge, attitude and practice of parents in obtaining medicines for children. Results: There was no significant difference socio-demographically between poor households in Klang Valley $(N=58)$ and East Coast $(N=40)$. The study found that access to medicine for children $(N=325)$ in the households was adequate, where all households that reported illness in the children over the last 1 month and the last 6 month periods, obtained medicines and $99 \%$ of the children were fully immunized. Qualitative analysis showed that poor households face several barriers in accessing medicines for their children such as financial, transportation, physical and attitudinal.

Conclusion: Access to medicines for children living in poor households in both areas were similar and adequate. However, barriers to access remain and further studies are required.
\end{abstract}

Keywords: Aaccess to medicine, Poor populations, Children, Klang Valley, Peninsular Malaysia

Tropical Journal of Pharmaceutical Research is indexed by Science Citation Index (SciSearch), Scopus, International Pharmaceutical Abstract, Chemical Abstracts, Embase, Index Copernicus, EBSCO, African Index Medicus, JournalSeek, Journal Citation Reports/Science Edition, Directory of Open Access Journals (DOAJ), African Journal Online, Bioline International, Open-J-Gate and Pharmacy Abstracts

\section{INTRODUCTION}

Access to medicines is a fundamental human right. This applies to all populations especially vulnerable populations such as people living in poverty as well as children [1]. Recognizing the need to address this, the World Health Organization (WHO) launched a campaign "Make medicines child size" to improve access to safe and appropriate medicines for children [2]. Access to medicines for children living in poor households remains a major interest in the global effort to improve child survival and health [3].
In Malaysia, the public health system, under the Ministry of Health, provides free healthcare and medicines for the population. Additionally, medicines can be obtained at the patient's own cost from private doctors who prescribe and dispense, and also from commercial pharmacies [4]. A study found that essential medicines in Malaysia are expensive and are not universally available [5], suggesting that problems may exist in accessing medicines especially by people with low incomes. There has been little research to 
investigate access to medicines for vulnerable populations where significant barriers could exist.

Despite the tremendous progress in economic and health development experienced by Malaysia over the last decades, there remain pockets of poverty-stricken households both in urban or rural areas [6]. In 2008, the Malaysian government initiated a registry, the eKasih, for households living below the poverty line as part of the effort to eradicate poverty in Malaysia [7]. This registry records households living below the poverty line from both self-registration and referrals from governmental or charity organizations.

The Klang Valley of Malaysia is regarded as the most urbanized and industrialized area in Malaysia with $100 \%$ urbanization rate for Kuala Lumpur and $88.3 \%$ for Selangor [8]. The average GDP per capita in Klang Valley is RM58,801 (approx. USD16,000). In contrast the East Coast has a much lower average GDP per capita at RM16,981 (approx USD4,500) [9] and is much more rural (urbanization rates: $33.5 \%$ for Kelantan, $49.4 \%$ for Terengganu). Although healthcare facilities are more numerous in urban centres, poor households may experience similar difficulty with those in rural areas, in accessing them to obtain treatment as well as medicine. This study aims to explore and compare the access to medicines for children living in poor households in the economically contrasting areas of Klang Valley and East Coast of Peninsular Malaysia.

\section{EXPERIMENTAL}

\section{Study population}

The sample population group are the households registered in the eKasih database [7]. Access to the eKasih database was approved by the Malaysian Prime Minister's department. The relevant information namely contact details, listed income and presence of children in the household was obtained from the database under secure and confidential arrangements.

\section{a) Inclusion criteria}

1) Caregiver registered with eKasih database

2) Household contains a child from 0-12 years of age

3) Caregiver of the child is a named registrant
4) Household income of less than RM110 (equivalent to USD30) per capita per month or USD1 per person per day

\section{b) Exclusion criteria}

1) eKasih registrants that live outside Peninsular Malaysia

2) Households that no longer fulfil the criteria of low income i.e. earning over RM110 per capita per month

3) Households that are not Malaysian citizens or permanent residents

Ethical approval was obtained from USIM's research ethics committee. A standard informed consent form complying with the stipulated requirements of the ethics committee and in the local language of Malay was prepared for all potential participants of the study.

\section{Study location}

The eKasih database contains the address and contact details categorized according to states in Malaysia. Klang Valley was classified as an area that includes the states of Selangor, Federal Territory of Kuala Lumpur and also Putrajaya that are predominantly urban areas; whereas East Coast is represented by the states of Kelantan and Terengganu, these states comprise some urban populations but with considerably larger rural areas [8].

\section{Sampling and instrumentation}

Registrants in the database within the states selected for the study was sampled randomly to obtain candidate caregivers to be contacted. The list for each state was displayed on a computer screen by one researcher, and a second researcher was asked to blindly click on the screen to select a candidate caregiver. The caregivers were initially contacted by phone and were asked whether they were willing to participate. Those that agreed were then visited at their home and was informed in detail of the study, including reassurances on the strict confidentiality of the information given. The interview was conducted after written informed consent was obtained from each caregiver.

A semi-structured interview was used to obtain both quantitative and qualitative information from the caregivers in the households identified. The semi-structured interview was a modification of the one developed by researchers at the University of Nottingham, United Kingdom to 
study children of refugee and asylum seekers in United Kingdom [10]. The primary modification was expanding the possible sources of medicine for the household children considering that for the UK study, all the refugee and asylum seekers were registered to a general practitioner. This interview session was conducted in Malay language and the questions were divided into five sections where most of the questions were restructured accordingly and adapted to be used in the Malaysian situation.

Section A - Demographical characteristics of the household including ages, household income per month, occupation, numbers of children, children's age, ethnicity and period of time living at home presently.

Section B - Health status of the caregiver and their health-seeking behavior.

Section C - Health problems of children in the household aged 12 years old and below, over the previous month from the interview, medicines administered to the children, place of treatment, medication costs and complimentary treatments, if any.

Section D - Health problems of children in the household aged 12 years old and below, over the last six month period from the interview, medicines administered to the children, place of treatment, medication costs and complimentary treatments, if any. Qualitative data was collected on whether there were any difficulties in obtaining medicines for both sections $C$ and $D$.

Section E - General knowledge of caregiver regarding epilepsy, asthma and febrile illness. A data collection/questionnaire sheet was used to record the information obtained from the interviews. The interviews were conducted between March 2012 and December 2013.

\section{Field work data management}

The entire information obtained from the interview session was transcribed onto the questionnaire sheets. Quantitative data was stored and analyzed using the software Social Package for Social Science (SPSS) version 13.0 (Chicago, Illinois).

\section{Data analysis}

Quantitative data in sections A, B, C and D were expressed using descriptive statistics. The student's T-test was used in significance testing. Statistical significance was set at $p<0.05$. A scoring method was used to analyse the data in section $\mathrm{E}$ regarding the caregiver's knowledge of epilepsy, asthma and febrile illness. The caregiver's knowledge, attitude and practice (KAP) in seeking medicine for their unwell child were determined. The method is a composite score based on aspects of immunisation programme awareness, knowledge on epilepsy, asthma and febrile illness and the caregiver's willingness to seek treatment and medication for their children.

The scoring scale used was as follows: 4.00 (> 4) showing a high level of KAP, $3.00-3.99$ score showing a medium level and score of less than 3.00 (< 3) showing a low level. Qualitative analysis was then used to clarify the questions on knowledge, attitudes and practices among participants in accessing medicines for their children in these poor households.

\section{RESULTS}

\section{Demographics}

A total of 98 poor households containing 325 children were visited and interviewed; 58 in the Klang Valley and 40 in the East Coast of peninsular Malaysia. The households were similar in terms of mean age of the interviewed caregiver (42 vs 43 years old). All 98 households had monthly per capita incomes below RM110 (USD30) per month, i.e. living on less than USD1.0 per person per day. The mean household monthly incomes were similar between both Klang Valley and East Coast (RM767.59 vs RM742.50, both approximately USD230). However households in the Klang Valley had a significantly lower number of children in the household (5 vs 6 , range $1-11$ vs $3-12, p=0.008$ ) (see Table 1).

\section{Caregivers' and children's health}

A similar proportion of caregivers in both areas reported themselves as being unhealthy (35\% vs $40 \%, p=0.67)$. The most commonly reported illnesses were asthma, hypertension, diabetes and migraine. There was one caregiver who was blind. The health status of the children in these poor households was also similar between the two areas. In the Klang Valley, 14/58 households $(24 \%)$ reported that their children had ongoing illnesses mainly consisting of asthma (12 children), while two other households had children with other illnesses namely febrile convulsion, hypothyroidism and pneumonia. In the East Coast households, 14/40 households (35\%) reported ongoing illnesses, 
Table 1: Demographic and health data for poor households in Klang Valley and East Coast

\begin{tabular}{|c|c|c|c|}
\hline Variable & $\begin{array}{r}\text { Klang Valley } \\
\mathrm{N}=58(\%)\end{array}$ & $\begin{array}{c}\text { East Coast } \\
N=40(\%)\end{array}$ & Mean / $\boldsymbol{P}$-value \\
\hline \multicolumn{4}{|c|}{ Interviewed caregiver } \\
\hline Mother & $35(60.3 \%)$ & $16(40.0 \%)$ & \multirow{3}{*}{-} \\
\hline Father & $19(32.8 \%)$ & $23(57.5 \%)$ & \\
\hline Guardian & $4(6.9 \%)$ & $1(2.5 \%)$ & \\
\hline \multicolumn{4}{|l|}{ Caregiver age (year) } \\
\hline $31-40$ & $29(50.0 \%)$ & 15 (37.5\%) & \multirow{5}{*}{$\begin{array}{c}42.2 \text { vs } 43.2 \\
p=0.564\end{array}$} \\
\hline $41-50$ & $23(39.7 \%)$ & $22(55.0 \%)$ & \\
\hline $51-60$ & $2(3.4 \%)$ & $2(5.0 \%)$ & \\
\hline $61-70$ & $3(5.2 \%)$ & $1(2.5 \%)$ & \\
\hline $71-80$ & $1(1.7 \%)$ & $0(0.0 \%)$ & \\
\hline \multicolumn{4}{|l|}{ Number of children } \\
\hline $0-4$ & $27(46.6 \%)$ & $7(17.5 \%)$ & \multirow{3}{*}{$\begin{array}{c}5 \text { vs } 6 \\
p=0.008\end{array}$} \\
\hline $5-9$ & $29(50.0 \%)$ & $30(75.0 \%)$ & \\
\hline $10-14$ & $2(3.4 \%)$ & $3(7.5 \%)$ & \\
\hline \multicolumn{4}{|c|}{ Monthly household income (RM) } \\
\hline $100.00-499.00$ & $8(13.8 \%)$ & $5(12.5 \%)$ & \multirow{3}{*}{$\begin{array}{c}\text { RM } 767.59 \text { vs } \mathrm{RM} 742.50 \\
p=0.702\end{array}$} \\
\hline $500.00-999.00$ & $34(58.6 \%)$ & $28(70.0 \%)$ & \\
\hline $1000.00-1500.00$ & $16(27.6 \%)$ & $7(17.5 \%)$ & \\
\hline \multicolumn{4}{|c|}{ Health status of caregiver } \\
\hline Healthy & $38(65.5 \%)$ & $24(60.0 \%)$ & \multirow[t]{2}{*}{$p=0.671$} \\
\hline Sick & $20(34.5 \%)$ & $16(40.0 \%)$ & \\
\hline \multicolumn{4}{|c|}{ Health status of children } \\
\hline Healthy & $44(75.9 \%)$ & $26(65.0 \%)$ & \multirow[t]{2}{*}{$p=0.263$} \\
\hline Sick & $14(24.1 \%)$ & $14(35.0 \%)$ & \\
\hline \multicolumn{4}{|l|}{ Immunisation } \\
\hline Yes & $57(98.3 \%)$ & $40(100.0 \%)$ & \multirow[t]{2}{*}{$p=1.000$} \\
\hline No & $1(1.7 \%)$ & $0(0.0 \%)$ & \\
\hline
\end{tabular}

12 households reported children with asthma, one household reported children with febrile convulsion and another household reported tonsillitis.

\section{Children's access to medicines over the preceding 1-month period}

From the 98 poor households in Klang Valley and East Coast, 55 (67\%) reported illnesses in the children over the preceding month from the interview session. In all the episodes of illnesses, medicines were obtained for the children. In 37 households, medicines were obtained from government healthcare facilities, while 8 households reported obtaining medicines from private hospitals or clinics. Another five (5) households purchased the medicines, three (3) bought over-the-counter (OTC) medicines from the pharmacy while two (2) bought medicines at general stores. Additionally, five households reused medicines kept from previous episodes when the children were unwell.

\section{Children's access to medicines over the preceding 6-months}

For the six months preceding the interview, 71 (72 \%) households reported having children with episodes of illness. Again, all 71 obtained medicines for the children. Fifty-two households obtained medicines from government facilities while 11 household obtained medicines from private facilities. The remainder bought the medicines from pharmacies (4) and general stores (4).

All households except for one, reported and showed evidence that their children were immunized according to the Malaysian Ministry of Health's childhood immunization programme [11]. Considering that all households that reported illnesses in their children were able to access medicines, a comparison of access between the areas was not required.

\section{Caregivers' knowledge, attitude and practice (KAP) in seeking medicine for children}

Composite scoring of the questionnaires for KAP showed that only 2 (2\%) of the 98 households were in the low category, while the majority of the households 96/98 (98\%) had appropriate KAP in seeking medicine for their children with 55/98 (56 $\%$ ) of the caregivers scoring high (> 4) in the composite scoring and 41 / 98 (42\%) scoring medium (3.0 - 3.9). There was no significant difference in the mean KAP scores between 
Klang Valley and the East Coast (mean scores $=$ 3.76 vs $3.72, p=0.56$ ).

\section{Barriers to accessing medicine for children}

Qualitative analysis of the interviews revealed that caregivers in these poor households faced certain barriers to accessing medicine for their children related to the following aspects; financial, transportation, physical/circumstantial and attitudinal. The aspects were interrelated with each other. The following excerpts (in italics) are direct quotations from the interviews but translated into English.

\section{a. Cost/financial}

Many of the caregivers mentioned that cost of the medicine is a barrier particularly when the most convenient healthcare facility to them is a private general practice clinic.

"The public clinic is so far away from here but I could not afford the cost of medicines from the private clinic which is nearer to my house."

"The private clinic or hospital is more efficient but I could not afford the cost. So I prefer buying the medicines such as paracetamol at the grocery shop and giving it to my child. If after two days my child does not recover only then l'll bring him/her to the clinic".

\section{b. Transportation problems}

The caregivers also expressed that another barrier that they face is difficulties with travelling to healthcare facilities. Although this barrier was mentioned more frequently in the East Coast, some caregivers felt that public transportation in the Klang Valley was not sufficiently affordable or convenient.

"The taxi fare is so expensive. I could not afford it. I'm not taking the bus since it is too difficult. So I'll bring only one child for treatment and the others will share the prescription with him/her.

"I only have a motorcycle. If the motorcycle breaks down, I will give my child leftover medicines from the last visit to health clinic".

\section{c. Physical/circumstantial}

Disability was found to be a significant barrier for affected caregivers in accessing medicines for the children in the household. They are dependent on supporting relatives, however this support is not always available.

"I'm a disabled person. If my children get sick, I always ask my family members to bring them for treatment. If no one is around I'll give medicines that I bought from the grocery store and give it to my child".

\section{d. Attitudinal}

Despite $98 \%$ of the households scoring well in the KAP composite scoring, qualitative analysis showed that certain beliefs exist as barriers to obtaining medicine for children in these households such as distrust in modern medicines and an overreliance on traditional remedies.

"I learned some massage techniques to treat illnesses so l'll massage my child at certain points on their body every time they complain of not feeling well. So far, they respond very well after the massages and we do not need modern medications".

"Sorry to say, I prefer not to bring my children to the doctors if they are unwell. If they are not feeling well I give them traditional or complimentary medicines. So far they respond well to it."

"I prefer not to give my children modern medicines. For cold, cough and flu, I used herbal plants to treat them. I plant them all in front of my house. For asthma, I will give them soup from eel and camel liver powder. So far it is working. My children are feeling good with it."

\section{DISCUSSION}

This study suggests that access to medicine for children living in poor households in Peninsular Malaysia appears to be adequate, both in urban locations of Klang Valley and also more rural areas in the East Coast of Malaysia. This is based on our findings that interviewed caregivers in the households managed to obtain medicines for all instances when their children became unwell in the preceding 1 month and 6 month periods prior to the interview.

The medicines were either prescribed and dispensed by government or private hospitals/clinics, bought over-the-counter (OTC) at local pharmacies (non-government) and general stores, but in some cases were reused from previous prescriptions or taken from 
medicines prescribed to other household members.

Although the findings on access are encouraging, this study has raised concerns on the whether the medicines are being given appropriately and safely. The US Food and Drug Administration (FDA) has recommended that OTC cold and cough products should not be given to children under 2 of ages due the risk of serious adverse effects [12]. Other studies have warned against the use of OTC analgesic medicines in children without consultation with a physician before use [13-15].

There were also some cases where the caregiver shared medicines prescribed to one child with other children in the household. This occurred mainly when leftover medicines from a prior visit were kept to be given for another episode of illness or to another child. This practice has been documented previously among Malaysian parents [16]. Although this is convenient for the caregivers, sharing prescription medicines potentially places the children at risk of adverse outcomes [17] as well as suboptimal therapy for the original prescription.

Almost all the households (97/98, $99.9 \%$ ) in our study reported that they had their children fully immunized. One household admitted that they did not obtain immunization for the household children as they believed it was unnecessary due to perceived low risk of contracting the diseases targeted by immunization and concerns on adverse effects. Nevertheless, the high immunization rate in this population was heartening particularly with the recent rise of the anti-immunization movements [18]. In Malaysia, evidence supports the childhood immunization programme as one of most cost effective interventions in preventing childhood diseases and reducing childhood mortality and morbidity [19].

The poor households in both urban and rural areas in this study appeared to have similar sociodemographical characteristics. Furthermore our study found that both populations were similar in terms of health status of both the caregivers and the children. Despite the seeming economic disparity between the Klang Valley and the East Coast, poor households seem to face similar barriers in obtaining medicine for their children. These barriers exist even as the rural healthcare services are being improved [20].

A prominent theme garnered from the qualitative information was an apparent mistrust of modern medicine and an overreliance on traditional remedies. Previous research has suggested that caregivers may be prone to misconceptions and distrust on medicines prescribed to their children [16]. This phenomenon has been previously documented even in developed or high-income countries [21]. This finding warrants further exploration and comparison with other studies, to support the development of public health strategies to overcome the negative perception of important childhood medicines.

Notwithstanding the positive findings on access, further exploration using qualitative methods revealed existing barriers to accessing medicines for children in this population. The interviewed caregivers described interrelated factors such as cost, convenience, transportation and disability acting as barriers to them accessing medicines for their children. Although many of the households obtained medicines at public facilities, which were free, several families bought medicines at their own cost. The relatively high cost of medicines at private facilities or pharmacist may influence the caregiver's behaviour in accessing medicines or managing their children's condition [22].

We believe that this is the first study investigating access to medicines in children living in poor households in Malaysia and among the very few studies on this issue globally. The findings will support local and national measures especially by the Ministry of Health to improve access and safe use of pediatric medicines in this population, as well as stimulate further research into this area with the goal of improving overall child health.

\section{Limitations of the study}

This study has several possible limitations. First, the eKasih database does not include certain populations such as aborigines, rural agricultural smallholders (both are managed by their specific governmental agencies) [23] and unregistered or illegal immigrant households. However future research studies are currently being planned to study access to medicines for children in these populations. Second, the responses obtained in this study might have been affected by recall bias since retrospective information is collected. Nevertheless, the conduct of face-to-face interviews in this study was meant to minimize this effect as it enabled the interviewers to double check information where possible. Thirdly, the relatively small numbers of households interviewed might limit the generalizability of the findings. However, the study was designed to focus on the poor population living on USD1 per person per day 
and these households are getting few and far between due to the rapid economic developments experienced in Peninsular Malaysia. Furthermore, the number of households interviewed in this study has provided important and useful quantitative information.

\section{CONCLUSION}

The findings of this study suggest that access to medicines in children living in poor households in urban Klang Valley and rural East Coast of Peninsular Malaysia appear to be adequate. However, the findings also reveal existing barriers to access in this population that require further research and possible interventional measures.

\section{ACKNOWLEDGEMENT}

The authors would like to thank the Implementation and Coordinating Unit (ICU) of the Malaysian Prime Minister's Department and all the caregivers who participated in the interviews. This study was funded by the Malaysian Ministry of Higher Education with a grant under Exploratory Research Grant Scheme (grant no. USIM/ERGS-PSK-52-50411).

\section{REFERENCES}

1. Hoppu K, Anabwani G, Garcia-Bournissen F, Gazarian M, Kearns GL, Nakamura $H$, Peterson RG, Sri Ranganathan S, de Wildt SN. The status of paediatric medicines initiatives around the world-what has happened and what has not? Eur J Clin Pharmacol 2012; 68: 1-10.

2. Watts G. WHO launches campaign to make drugs safer for children. BMJ 2007; 335: 1227.

3. Choonara I. Why children do not receive treatment. Arch Dis Child 2014; (99): 605-606.

4. Babar ZU, Izham M Ibrahim M, Bukhari NI. Medicine utilization and pricing: The findings of a household survey in Malaysia. J Gener Med. 2005; (3): 47-61.

5. Babar ZUD, Ibrahim MIM, Singh H, Bukahri NI, Creese A. Evaluating Drug Prices, Availability, Affordability, and Price Components: Implications for Access to Drugs in Malaysia. Harvey K, Ed. PLoS Medicine 2007; 4(3): e82.

6. Gopal PS, Malek NM. Breaking away from the cycle of poverty: The case of Malaysian poor. The Soc Sci J. 2015; 52(1): 34-39.

7. Government Transformation Programme 2.0. Raising Living Standards of Low Income Households. Government Transformation Program, Performance Management Delivery Unit, Government of Malaysia. Available from: URL:
http://www.pemandu.gov.my/gtp/Raising_Living_Standa rds_of_Low_Income_Households-@-

GTP_2@0_Raising_Living_Standards_of_Low_Income _Households.aspx [Cited 2014 December 7].

8. Jaafar J. Emerging trends of urbanisation in Malaysia. J.Msian Dept of Statistics Malaysia 2004; (1): 43-54.

9. Department of Statistics Malaysia. State/District Data Bank 2012. Putrajaya, Malaysia.

10. Alkahtani S, Cherrill J, Millward C, Grayson K, Hilliam R, Sammons H, Choonara I. Access to medicines by child refugees in the East Midlands region of England: a cross-sectional study. BMJ Open 2014-006421.

11. Ministry of Health Malaysia. Malaysian Immunization Schedule 2014. Available from: URL http://myhealth.gov.my/index.php/en/immunisationschedule [Cited 5 December 2014].

12. Briars $L A$. The latest update on over-the-counter cough and cold product use in children. J Pediatr Pharmacol. Ther. 2009; 14(3): 127-131.

13. Du $Y$, Knopf $H$. Self-medication among children and adolescents in Germany: results of the National Health Survey for Children and Adolescents (KiGGS). Brit $J$ Clin Pharmaco 2009; 68: 599-608.

14. Arencibia ZB, Choonara I. Balancing the risks and benefits of the use of over-the-counter pain medications in children. Drug Safety 2012; 35: 1119-1125.

15. Nor Aripin KNB, Choonara I. The Management of Paracetamol Poisoning. Paediatr Child Health (Oxford) 2009; 19: 492-497.

16. Chan G, Tang S. Parental knowledge, attitudes and antibiotic use for acute upper respiratory tract infection in children attending a primary healthcare clinic in Malaysia. Singapore Med J. 2006; 47(4): 266-70.

17. Goldsworthy RC, Schwartz NC, Mayhorn CB. Beyond abuse and exposure: framing the impact of prescriptionmedication sharing. Am J Public Health 2008; 98: 1115.

18. Jolley $D$, Douglas KM. The effects of anti-vaccine conspiracy theories on vaccination intentions. PloS One 2014; 9: e89177.

19. Othman N, Menon BS, Azlyna MYY. Risks Factors Associated With Incomplete Immunisations In Hospitalised Infants. Med J Malays 2005; 60(5):563569.

20. Ariff KM, Teng CL. Rural health care in Malaysia. Aust $J$ Rural Health 2002; 10: 99-103.

21. Rajakumar K, Thomas SB, Musa D, Almario D, Garza MA. Racial differences in parents' distrust of medicine and research. Arch Pediatr Adolesc Med 2009; 163: 108-114.

22. Schafheutle El, Hassell K, Noyce PR. Access to medicines: cost as an influence on the views and behaviour of patients. Health Soc Care Community 2002; 10: 187-195.

23. Merican I, bin Yon R. Health care reform and changes: the Malaysian experience. Asia- Pac J Public Health 2002; 14: 17-22. 